\title{
WAVE FLUME-BASED EVALUATION OF SUSPENDED SAND TRANSPORT IN BREAKING WAVES
}

\author{
Junichi Otsuka ${ }^{1}$, Yasunori Watanabe ${ }^{2}$
}

\begin{abstract}
In this study, suspended sediment concentration and velocity in surf zones was measured in a small-scale wave flume with three breaker types (plunging, spilling and intermediate) using an optical concentration sensor and an ultrasonic velocity profiler (UVP). The sediment pickup rate was also calculated from the depth-averaged concentration and the wave energy flux dissipation rate. In plunging breakers, relatively large amounts of sediment are suspended in the transition region due to strong three-dimensional turbulent flows generated by large-scale vortices. In spilling breakers, sediment concentration is lower than that seen in plunging breakers because smaller- scale vortices typically develop below the water surface in the transition region. Concentrations in both breaker types remain at lower levels in bore regions because the vortices fully develop into weak turbulent bores. Comparison in the same range of wave energy flux dissipation rates showed that the sediment pickup rates in these small-scale experiments were approximately $10^{3}$ times greater than those calculated by Goda (2010) using various data compiled from large-scale experiments and field observations.
\end{abstract}

Keywords: breaking wave, sediment transport, suspended sediment pickup rate, ultrasonic velocity profiler (UVP)

\section{INTRODUCTION}

Velocity fields and suspended sediment concentration in surf zones have been extensively investigated in laboratory experiments and field observations over recent decades. However, sediment transport processes and rates have not been quantitatively clarified because complex three-dimensional turbulent flows generated by breaking waves are the predominant mechanism behind sediment suspension and transport. In surf zones, plunging jets of breaking waves sequentially splash onto the water surface ahead, producing horizontal roller vortices beneath jets and longitudinal counter-rotating vortices behind rollers (Watanabe et al., 2005). These vortices generate three-dimensional turbulent flows, which enhance sediment suspension (Nadaoka et al., 1989). The processes of development for these vortices differ by breaker type (typically either with plunging or spilling breakers). In a plunging breaker, jets overturning from the wave crest touch down at the plunging point where plunging occurs, forming horizontal roller vortices, and secondary jets successively produce an array of roller vortices. As dynamic splash-up continues in the transition region, successive plunging jets serve to locally intensify strong turbulence, leading to the appearance of fully developed turbulent bores in the bore region. In a spilling breaker, the wave crest spills down the water surface ahead to produce smaller roller vortices. Initially, only weak turbulence is generated, and this gradually develops into turbulent bores. Accordingly, to further elucidate sediment transport in surf zones, sediment transport processes and rates should be examined in relation to the process of development for turbulent flows generated by breaking waves.

In this study, temporal variations in the cross-shore distribution of wave heights, suspended sediment concentrations and velocities in surf zones were measured in a small-scale wave flume for three breaker types. In addition, assuming a state of equilibrium in depth-averaged concentration, sediment pickup rates were estimated from depth-averaged concentration and the wave energy flux dissipation rate with comparison to the rates calculated by Goda (2010) using various data compiled from large-scale experiments and field observations.

\section{EXPERIMENTAL SETUP AND CONDITIONS}

The experiments were performed in a wave flume of $24.0 \mathrm{~m}$ in length, $0.4 \mathrm{~m}$ in width and $1.0 \mathrm{~m}$ in depth with a piston-type wave generator at one end (Figure 1). The still water depth in the constantdepth region of the flume was $0.6 \mathrm{~m}$ in all experiments. A well-sorted sand bed was installed in the flume to create a uniform 1:20 slope. The median grain diameter of the sand bed was $0.20 \mathrm{~mm}$. Suspended sand concentration, suspended sand velocity and water surface elevation in surf zones over the sloped bed were simultaneously measured using an optical concentration sensor, an ultrasonic velocity profiler (UVP, METFLOW) and a capacitance-type wave gauge, respectively. The UVP is a device for measuring instantaneous velocity profiles along the ultrasonic beam axis by detecting the Doppler shift frequency of ultrasound reflected from suspended particles in liquid. Takeda (1995) performed UVP measurement for diverse flow configurations and examined the applicability of the technique. O'Donoghue \& Wright (2004) used a UVP to measure velocity profiles for sand in oscillatory sheet flow conditions, and presented the UVP as capable of measuring deep within the sheet

\footnotetext{
${ }^{1}$ Civil Engineering Research Institute for Cold Region, Hiragishi 1-3-1, Sapporo, 0608628 Japan

${ }^{2}$ School of Engineering, Hokkaido University, North 13 West 8, Sapporo, 0608628 Japan
} 
(a) Side view

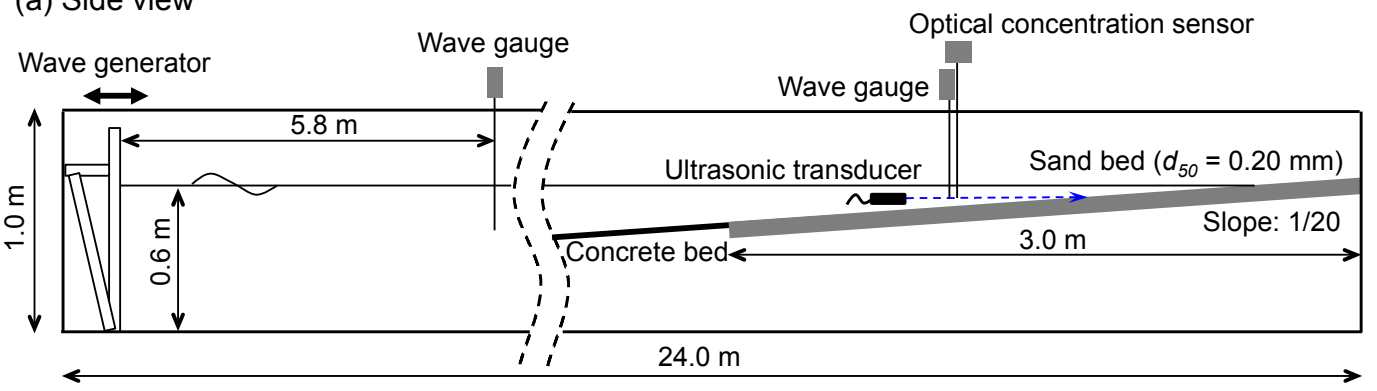

(b) Plane view

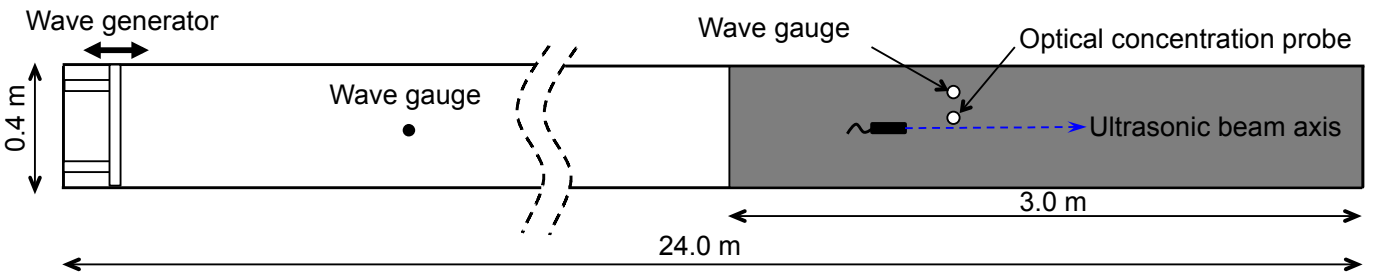

Figure 1. Experimental setup.

(a) In the case of the horizontal velocity measurement

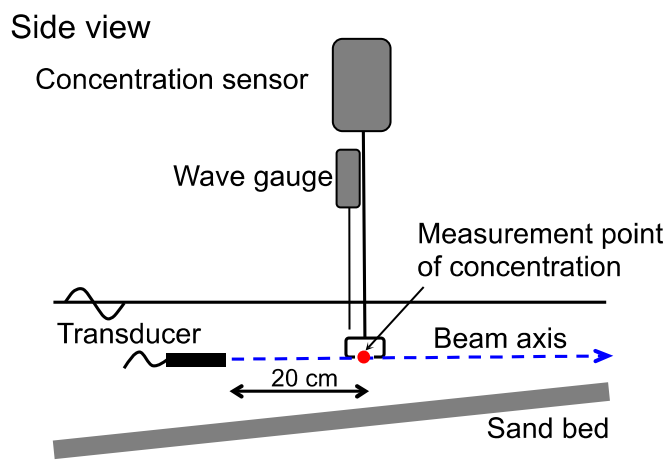

Plane view

Side wall of flume

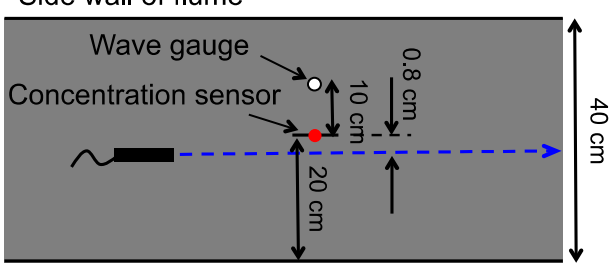

Side wall of flume (b) In the case of the vertical velocity measurement

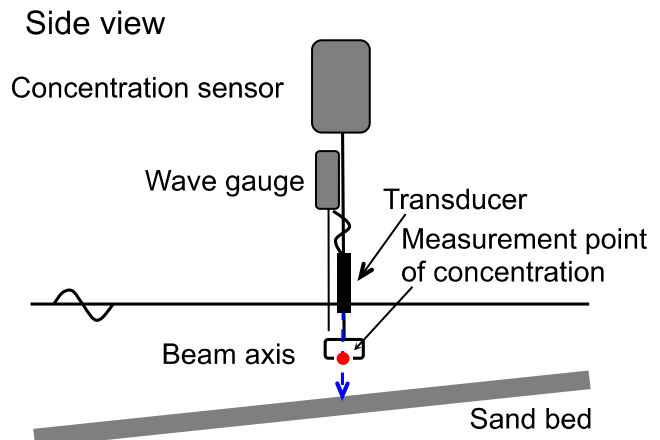

Plane view

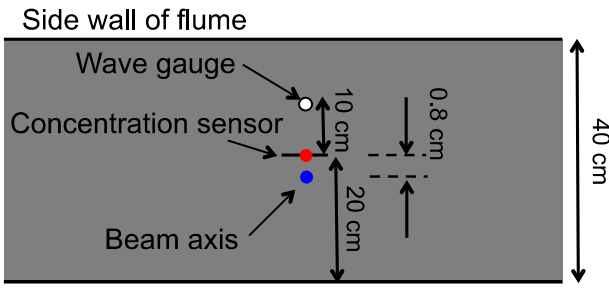

Side wall of flume

Figure 2. Arrangement of measuring instruments.

flow layers with high concentration. The optical concentration sensor was located at a measurement point along the centerline of the flume. To determine the horizontal cross-shore velocity and vertical velocities, an ultrasonic beam was horizontally and vertically emitted from a transducer to the measurement point (Figure 2). For horizontal velocity measurement, the transducer was placed $20 \mathrm{~cm}$ from the measurement point in the offshore direction (Figure 2 (a)). For vertical velocity measurement, the transducer was set approximately $1 \mathrm{~cm}$ below the wave trough level (Figure 2 (b)). The instantaneous velocity at the measurement point was determined from the measured velocity profiles. The ultrasonic beam was emitted with a spacing of $8 \mathrm{~mm}$ from the sensor tip to avoid interference with 


\begin{tabular}{|c|c|c|c|c|c|c|}
\hline & $\begin{array}{c}T \\
\text { (s) }\end{array}$ & $\begin{array}{c}H_{b} \\
(\mathrm{~cm})\end{array}$ & $\begin{array}{c}h_{b} \\
(\mathrm{~cm})\end{array}$ & $\begin{array}{l}\text { Bottom } \\
\text { slope }\end{array}$ & $\begin{array}{c}\text { Surf } \\
\text { similarity } \\
\text { parameter }\end{array}$ & Breaker type \\
\hline CASE 1 & 1.4 & 12.5 & 13.8 & $1 / 20$ & 0.337 & Plunging \\
\hline CASE 2 & 1.8 & 14.7 & 15.0 & $1 / 20$ & 0.293 & $\begin{array}{l}\text { Spilling- } \\
\text { Plunging }\end{array}$ \\
\hline CASE 3 & 2.0 & 13.7 & 14.1 & $1 / 20$ & 0.247 & Spilling \\
\hline
\end{tabular}

(a) CASE 1

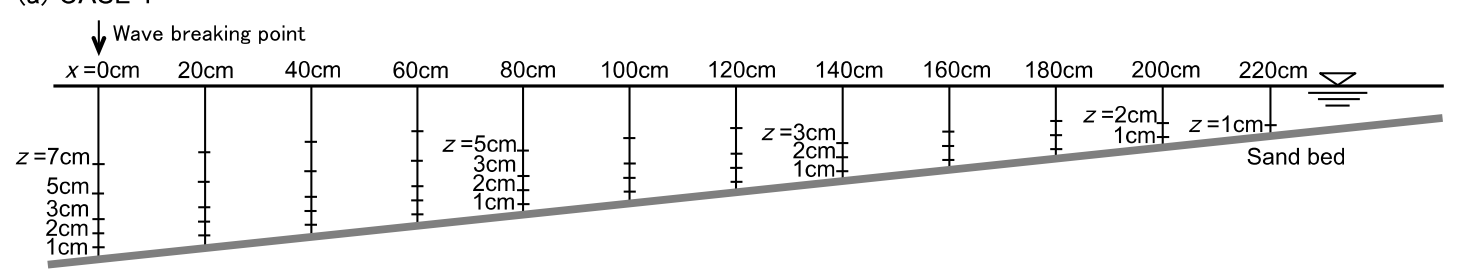

(b) CASE 2

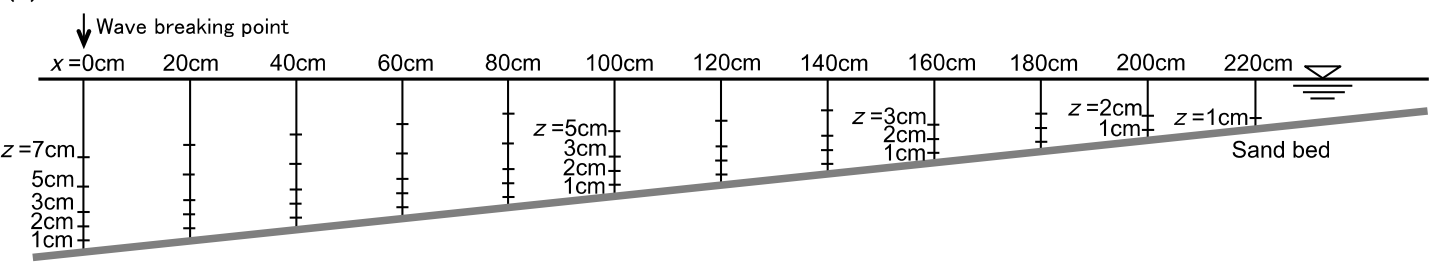

(c) CASE 3

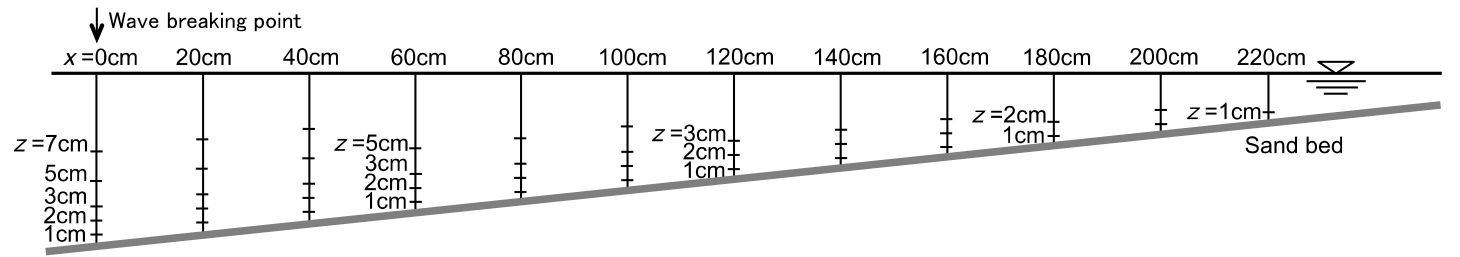

Figure 3. Measurement locations.

ultrasound propagation. The sampling spacing for the velocity profiles along the ultrasonic beam was $1.5 \mathrm{~mm}$, and the velocity resolution was $7.1 \mathrm{~mm} / \mathrm{s}$. The acoustic frequency was $2 \mathrm{MHz}$. The transducer measured $60 \mathrm{~mm}$ in length and $12 \mathrm{~mm}$ in diameter. A wave gauge was set $10 \mathrm{~cm}$ from the measurement point in the transverse direction of the flume. The concentration sensor, UVP and wave gauge were triggered by a TTL signal generated when a wave gauge installed in front of the wave paddle detected the first wave. The data acquisition frequency of these instruments was $100 \mathrm{~Hz}$. Waves were generated for 30 seconds and the sand bed was flattened before each wave was generated. As the bed form changed little throughout the period, bed features such as ripples were not considered in this study.

The experiments were conducted with three regular wave conditions as shown in Table 1 . The major factors considered were the wave period $T$ (or the deep-water wavelength $L_{0}$ via the dispersion relationship), the breaking wave height $H_{b}$, the breaking water depth $h_{b}$ and the bottom slope $\theta$. The surf similarity parameter $\xi$ was given as $\xi=\tan \theta / \sqrt{H_{b} / L_{0}}$. The wave breaker types were plunging breaker in Case 1, intermediate breaker in Case 2 and spilling breaker in Case 3.

The measurement locations in the cross-shore direction were set from the wave breaking point to the shoreline at $20 \mathrm{~cm}$ intervals (Figure 3). At each location, the concentration and, horizontal/ vertical velocities were measured at one to five elevations from $1 \mathrm{~cm}$ above the bottom to below the wave trough level. Ten measurements were taken at each measurement point to allow evaluation of ensemble-averaged values. The horizontal coordinate $x$ was defined as positive onshore with $x=0$ at the wave breaking point for each wave condition. The vertical coordinate $z$ was defined as positive upward with $z=0$ at the initial bottom level for each measurement location. 

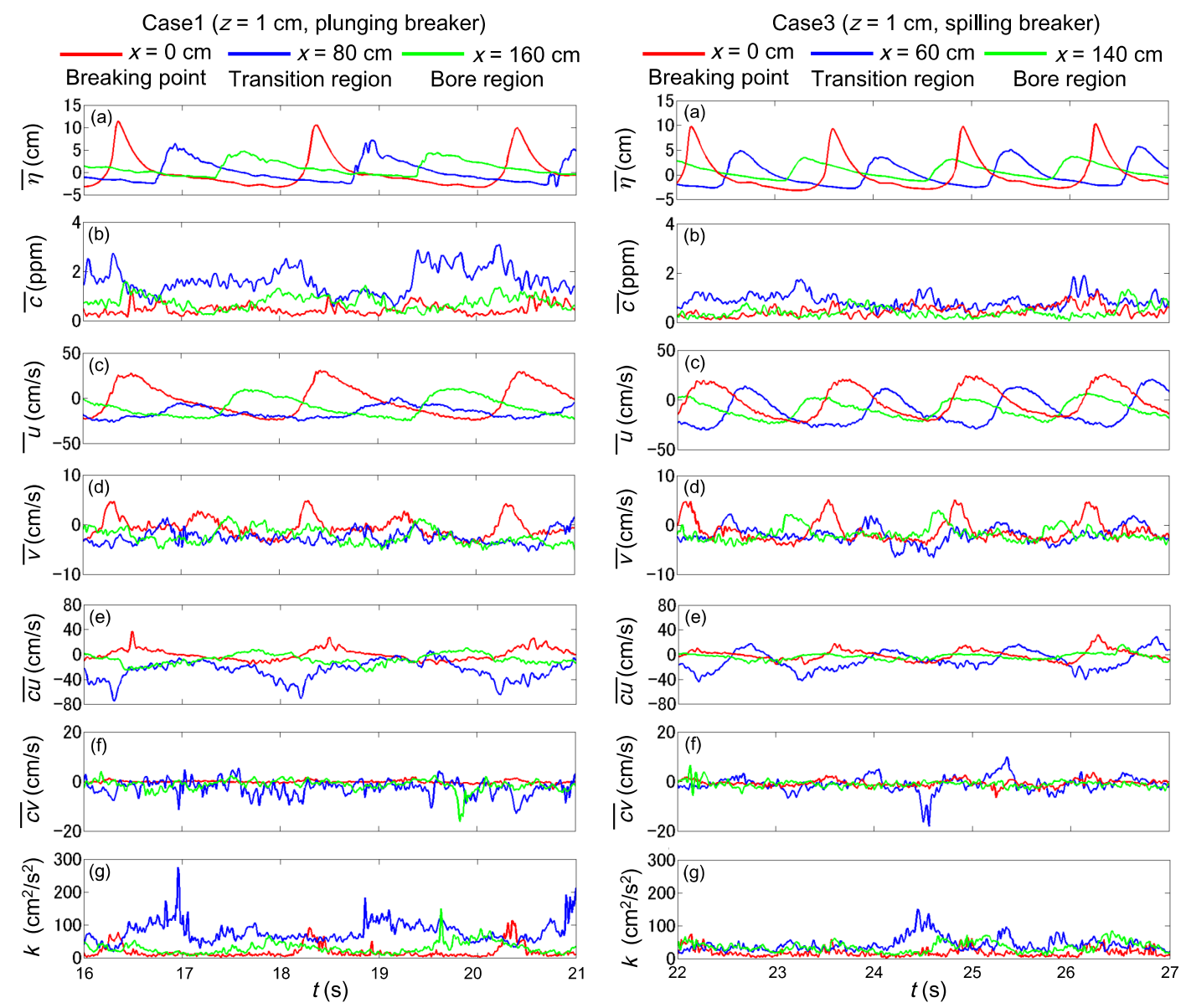

Figure 4. Temporal variations of ensemble-averaged (a) surface elevation, (b) suspended sand concentration, (c) horizontal velocity, (d) vertical velocity, (e) horizontal flux, (f) vertical flux, and (g) turbulent energy for the breaking point (red lines), the transition region (blue lines) and the bore region (green lines) at $z=1 \mathrm{~cm}$ in cases 1 (left) and 3 (right).

\section{RESULTS}

Figure 4 shows temporal variations in ensemble-averaged (a) surface elevation $\bar{\eta}$, (b) suspended sand concentration $\bar{c}$, (c) horizontal velocity $\bar{u}$, (d) vertical velocity $\bar{v}$, (e) horizontal flux $\overline{c u}$, (f) vertical flux $\bar{c} \bar{v}$, and (g) turbulent energy $k$ for the wave breaking point, transition region and bore region at $z=$ $1 \mathrm{~cm}$ for cases 1 and 3 . The symbol denotes ensemble-averaging operation for instantaneous values. Turbulent energy is defined as $k=\left(\overline{u^{\prime 2}}+\overline{v^{\prime 2}}\right) / 2$, where $u^{\prime}=u-\bar{u}, v^{\prime}=v-\bar{v}$. In both cases, the onshore and upward velocities (i.e., positive velocities) at the breaking point were much higher than those in the transition region and bore region when a wave crest passed. In contrast, the sand concentration, flux and turbulent energy at the breaking point showed relatively small values. In the plunging breaker, the concentration, flux and turbulent energy significantly increased in the transition region after a wave crest passed, as the large-scale vortices that typically develop generated strong three-dimensional turbulence, thereby affecting sediment suspension. As horizontal sand flux showed large negative values, it can be considered that suspended sediment in the transition region was extensively transported offshore after a wave crest passed. In the spilling breaker, the concentration, flux and turbulent energy were lower than those in the plunging breaker because smaller-scale vortices typically develop below the water surface in the transition region, and cannot easily reach the bottom. In both cases, concentration and turbulent energy in the bore region showed relatively small values compared to those in the transition region because the vortices fully developed into weak turbulent bores in the bore region.

Figure 5 shows time-averaged concentration profiles for each location. The blue dots represent measured values, and the red lines are approximated curves for the profiles measured at each location based on the following exponential function: 
(a) Case 1

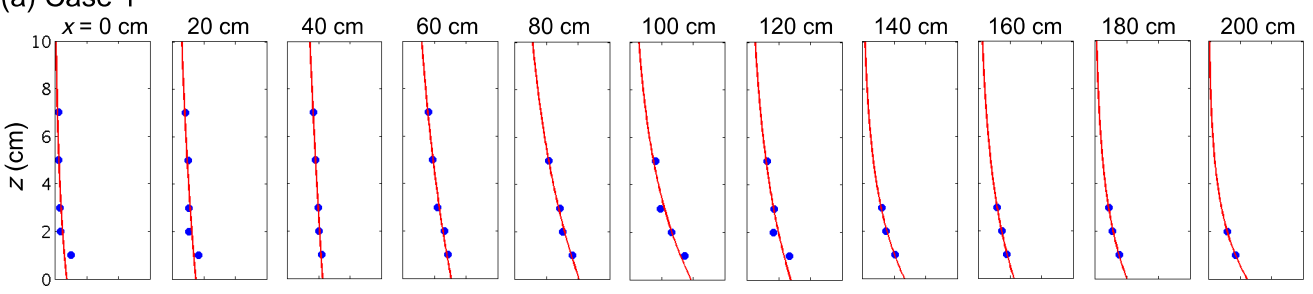

(b) Case 2
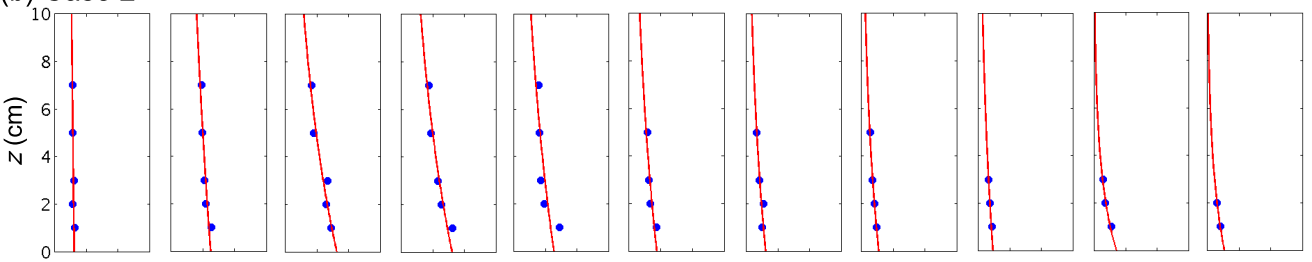

(c) Case 3

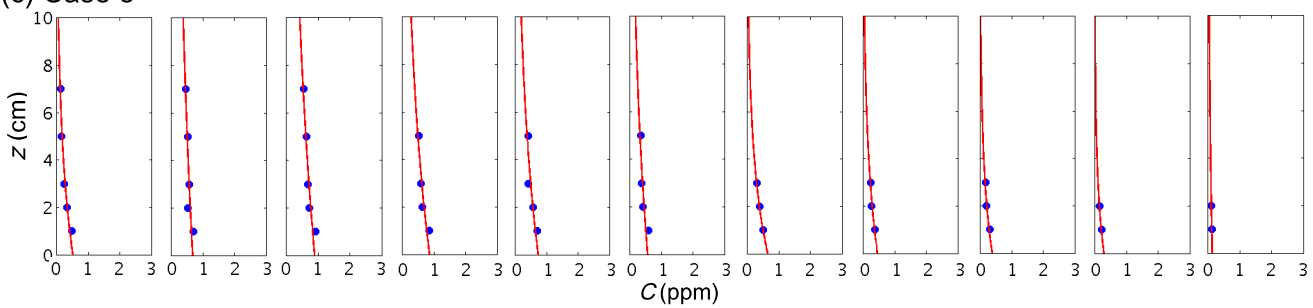

Figure 5. Time-averaged concentration profiles for each location (blue dots: measured values, red lines: approximated curves).
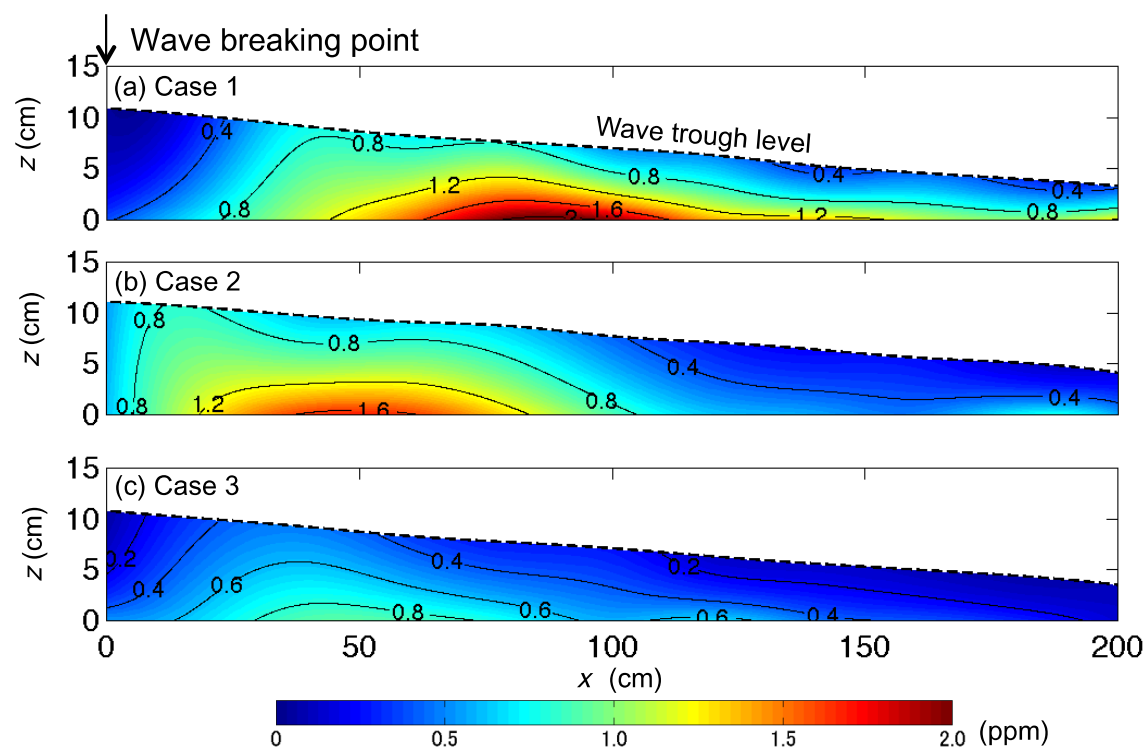

Figure 6. Colored contours of time-averaged concentration.

$$
C(z)=C_{0} e^{a z}
$$

where $C$ is the time-averaged concentration determined from the ensemble-averaged concentration, $C_{0}$ is the concentration at the bottom, and $a$ is the rate of concentration decrease. $C_{0}$ and $a$ are estimated using the least-squares method for the measured concentration profiles. The results indicate that the approximated curves correspond closely to the measured profiles for each location. Interpolating the approximated curves with respect to the $x$-axis based on the cubic spline method, colored contours of time-averaged concentration were obtained as shown in Figure 6. These contour figures represent cross-shore distributions of time-averaged concentration varying by breaker type. Concentration around 
(a) Case 1

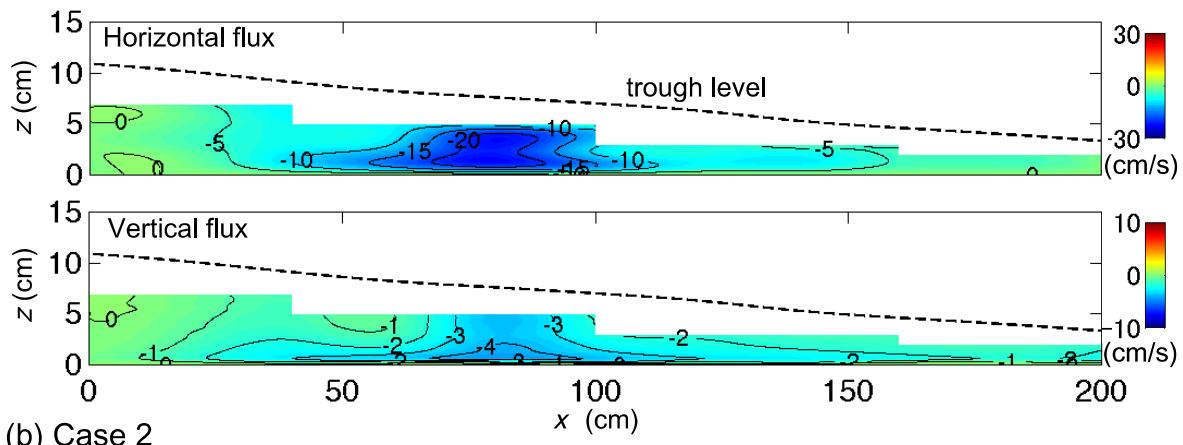

(b) Case 2
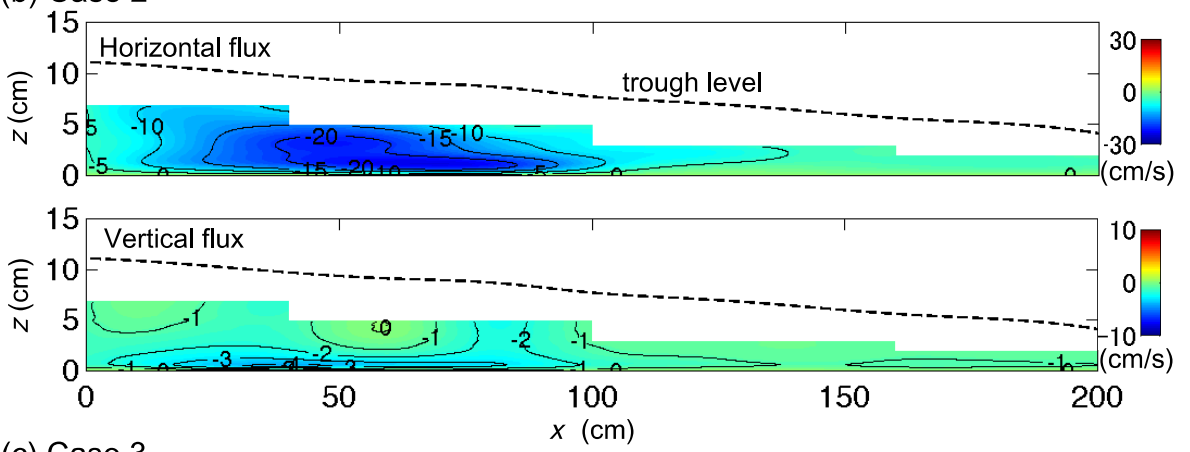

(c) Case 3
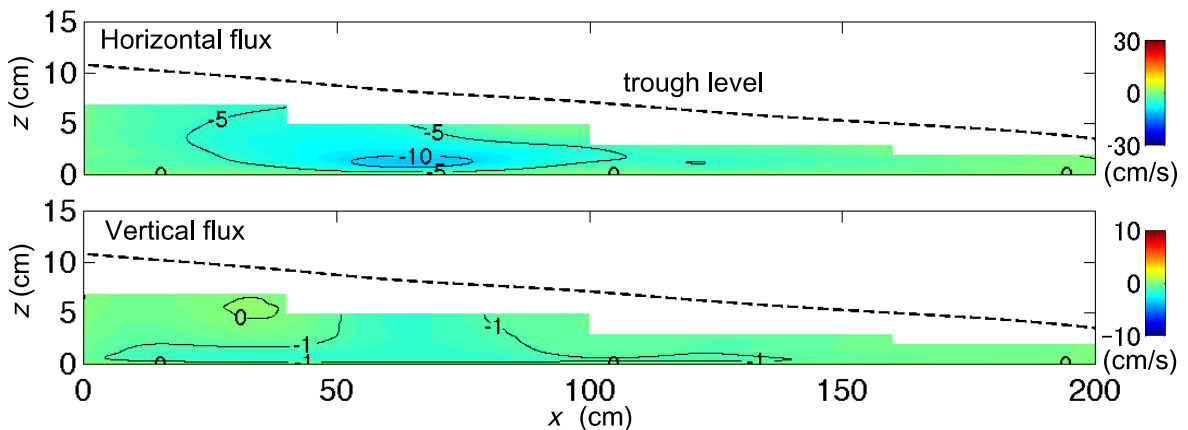

Figure 7. Colored contours of time-averaged horizontal and vertical sediment flux.

the transition region in the plunging breaker (Case 1) and the intermediate breaker (Case 2) was much higher than that in the spilling breaker, and gradually decreased toward the shore because turbulence intensity weakens with wave propagation.

Figure 7 shows colored contours of time-averaged horizontal and vertical sediment flux obtained by applying the same interpolation as that of Figure 6 to the measured horizontal and vertical fluxes. In each case, negative horizontal and vertical fluxes (i.e., offshore and downward fluxes) appeared around the high concentration region. It can be inferred that the time-averaged offshore flux was influenced by the undertow that developed below the wave trough level after a wave crest passed. As relatively small negative time-averaged vertical velocity values are seen for each location due to sediment settling velocity, it can be considered that large downward flux appeared in the high- concentration region.

Goda (2011) estimated sediment pickup rates in surf zones using a database of suspended sediment concentrations and wave energy flux dissipation rates compiled from various data obtained in largescale experiments and field measurements. The estimation method is outlined below.

The physical power for maintaining the concentration constant can be expressed by:

$$
d J_{s}=\int_{0}^{h}\left(\rho_{s}-\rho_{w}\right) \cdot g \cdot C_{a} \cdot w_{f} d t d z
$$

where $h$ is the still water depth, $\rho_{s}$ is the sediment density, $\rho_{w}$ is the water density, $g$ is the gravity acceleration, $C_{a}$ is the depth-averaged concentration and $w_{f}$ is the sand settling velocity. The wave 


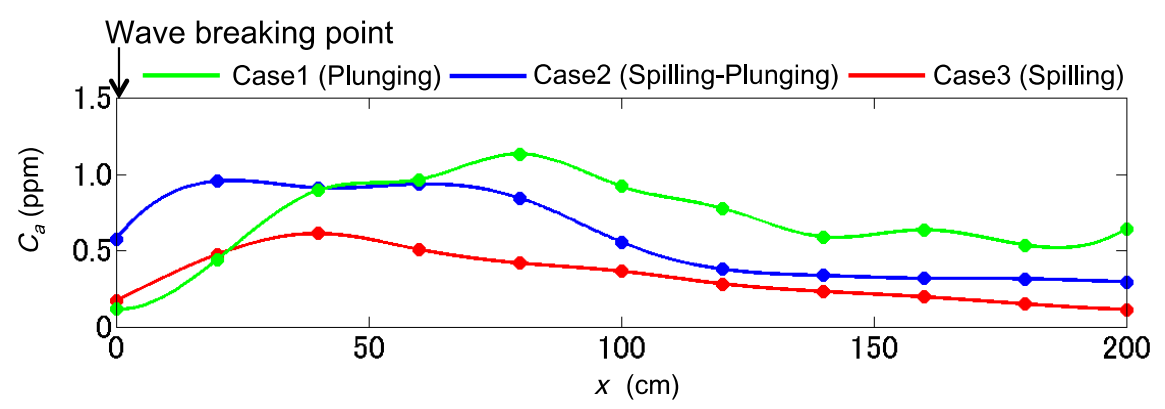

Figure 8. Cross-shore distributions of depth-averaged concentration.

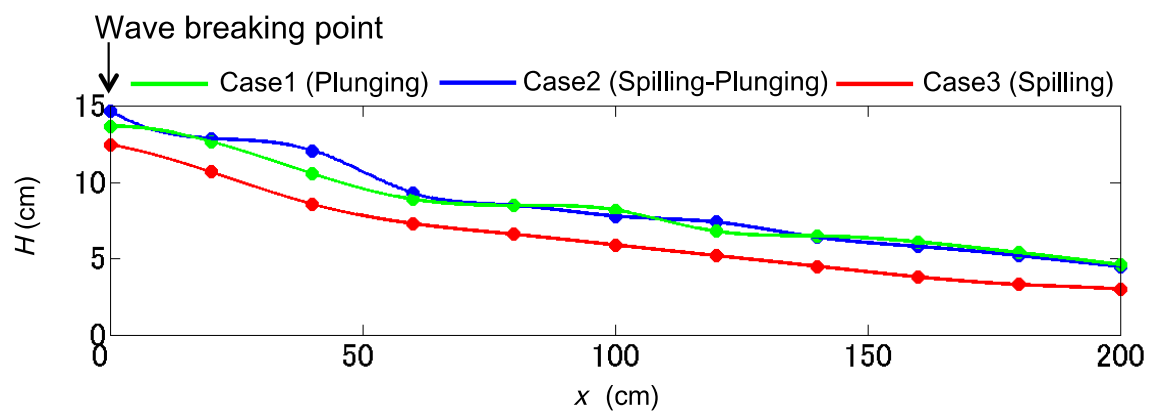

Figure 9. Cross-shore distributions of wave height.

energy flux dissipation rate $W_{D}$ can be expressed by

$$
W_{D}=\frac{1}{8} \cdot \rho_{w} \cdot g \cdot \frac{\partial}{\partial x}\left[H^{2} \cdot c_{g} \cos \theta\right]
$$

where $H$ is the wave height, $c_{g}$ is the group velocity and $\theta$ is the wave direction. In this study, the group velocity $c_{g}$ was given by $\sqrt{g h}$. Assuming that a portion of $W_{D}$ is consumed in maintaining the concentration constant, the following equation is obtained:

$$
\frac{d J_{s}}{d t}=\beta \cdot W_{D}
$$

where $\beta$ is the sediment pickup rate. Assigning equations (2) and (3) to equation (4), the sediment pickup rate $\beta$ can be expressed as followings:

$$
\beta=\frac{C_{a} \cdot\left(\rho_{s}-\rho_{w}\right) \cdot g \cdot w_{f} \cdot h}{W_{D}}
$$

where $\rho_{s}=2,650 \mathrm{~kg} / \mathrm{m}^{3}, \rho_{w}=1,000 \mathrm{~kg} / \mathrm{m}^{3}$ and $g=9.81 \mathrm{~m} / \mathrm{s}^{2}$. The depth-averaged concentration $C_{a}$ is determined from the approximated curve of the time-averaged vertical concentration profile shown in Figure 5. The cross-shore distribution for depth-averaged concentration is shown in Figure 8. The sand settling velocity $w_{f}$ in a water tank is $2.48 \mathrm{~cm} / \mathrm{s}$, as measured using particle image velocimetry (PIV). The wave energy flux dissipation rate $W_{D}$ is calculated from the cross-shore distribution of wave height shown in Figure 9, in which the wave height distribution measured at $20 \mathrm{~cm}$ intervals was interpolated at intervals of $0.1 \mathrm{~cm}$ using a cubic spline function.

Figure 10 shows cross-shore distributions of the wave energy flux dissipation rate $W_{D}$. In each case, the rate decreases from the breaking point to the transition region, and little change is seen in the bore region. The rate varies little by breaker type in the bore region.

Figure 11 shows cross-shore distributions of the sediment pickup rate $\beta$. Although the wave energy flux dissipation rate $W_{D}$ shows relatively large values around the breaking point, the pickup rate is small; it gradually increases from the breaking point and reaches its maximum value in the transition 


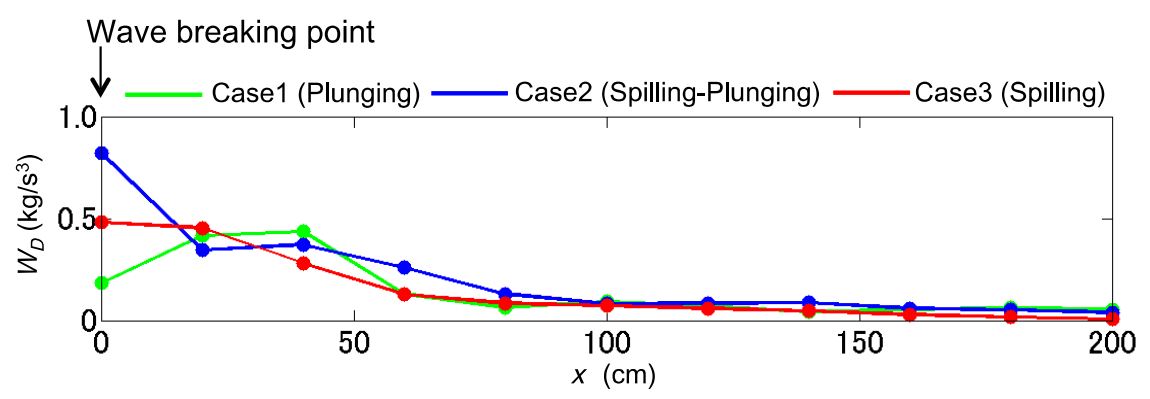

Figure 10. Cross-shore distributions of the wave energy flux dissipation rate.

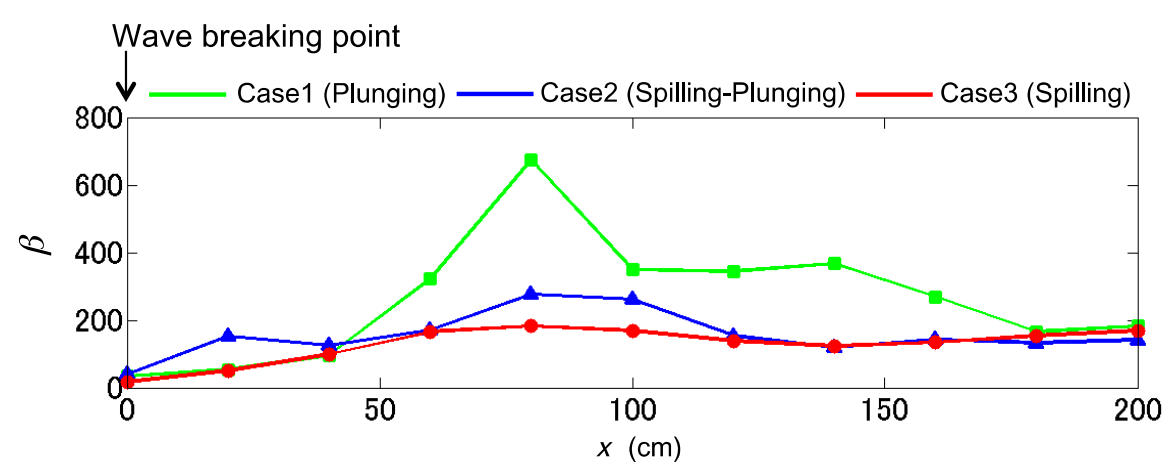

Figure 11. Cross-shore distributions of the sediment pickup rate.

region. The peak value in the plunging breaker is much higher than that in the other breakers. In the bore region, relatively high values are seen in the pickup rate for the plunging breaker.

Figure 12 plots the sediment pickup rate $\beta$ versus the wave energy flux dissipation rate $W_{D}$ as calculated from the small-scale experiment data. The pickup rate tends to decrease with higher wave energy flux dissipation rates. Relatively high values are seen in the pickup rate for the plunging breaker (Case 1), especially in the range of $W_{D}<10^{-1} \mathrm{~kg} / \mathrm{s}^{3}$.

Figure 13 plots the sediment pickup rate $\beta$ versus the wave energy flux dissipation rate $W_{D}$ as calculated by Goda (2010) using various data from field measurements and large-scale experiments. Compared in the range of $10^{-2}<W_{D}<10^{-0} \mathrm{~kg} / \mathrm{s}^{3}$, the pickup rate seen in this study's small-scale experiments (Figure 12) is between approximately 20 and 700, and the pickup rate calculated from large-scale data is between approximately 0.004 and 10 . These results indicate that the concentration of suspended sediment in small-scale experiments is significantly higher than that in large-scale measurements with the same wave energy flux dissipation rate. It can be inferred that the relative scale of vortices or turbulent intensity that cause sediment suspension in large-scale measurements are much smaller than those in small-scale experiments. Consequently, the measurement scale has a significant influence on sediment transport processes and rates in surf zones.

\section{CONCLUSIONS}

In this study, temporal variations in the cross-shore distribution of suspended sediment concentration and velocity in surf zones were measured in a small-scale wave flume with three breaker types (plunging, spilling and intermediate) using an optical concentration sensor and an ultrasonic velocity profiler (UVP). The sediment pickup rate in surf zones was also evaluated from depthaveraged concentration and the wave energy flux dissipation rate.

Sediment transport processes and rates vary by breaker type. In a plunging breaker, large-scale vortices produced in the transition region stir up large amounts of sediment. In a spilling breaker, suspended sand concentration in the transition region is lower than that in a plunging breaker because weaker turbulence typically develops below the water surface, and cannot easily reach the bottom. In both breaker types, turbulent intensity decreases with wave propagation, developing into turbulent bores in the bore region. As a result, sediment concentration in the bore region remains relatively low.

The sediment pickup rate in this study's small-scale experiments was much higher than that 


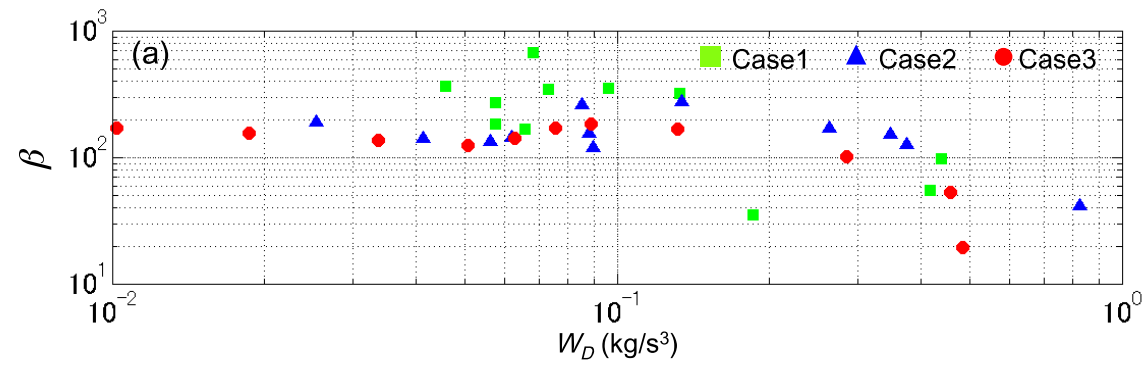

Figure 12. Plot of sediment pickup rates versus wave energy flux dissipation rates in this study's smallscale experiments.

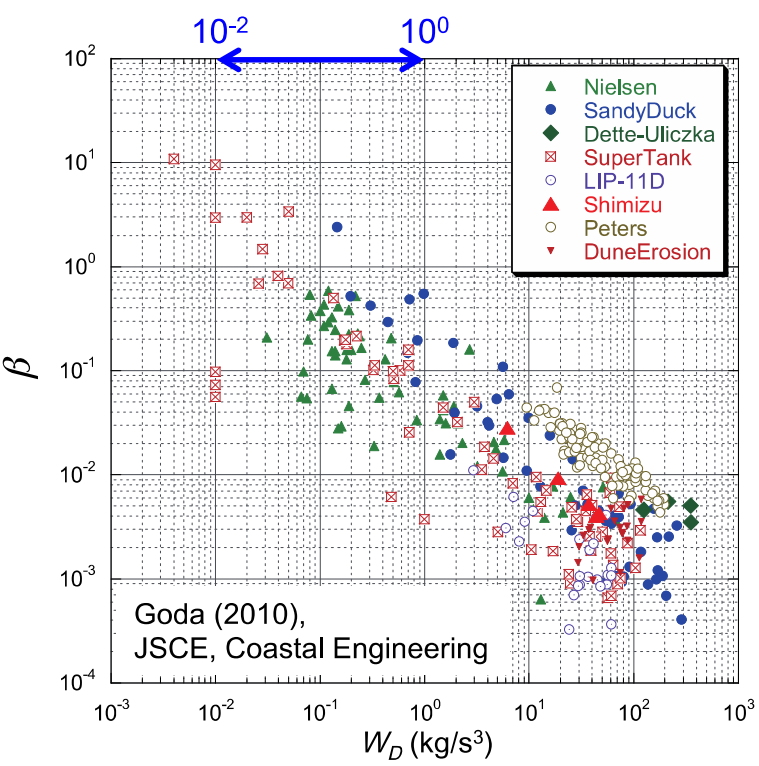

Figure 13. Plot of sediment pickup rates versus wave energy flux dissipation rates as calculated by Goda (2010) using various data from large-scale experiments and field observations.

calculated by Goda (2010) using various data from large-scale experiments and field observations. It can be inferred that the relative scale of vortices causing sediment suspension is much larger in smallscale measurements than in large-scale ones.

\section{ACKNOWLEDGMENTS}

Financial support for this study was provided by a JSPS Grant-in-Aid for Scientific Research (22760378).

\section{REFERENCES}

Goda, Y., 2010, Quantitative assessment of sediment pickup rate within surf zone based on large-scale data, Proceedings of Coastal Engineering, JSCE, 66, 421-425 (in Japanese).

Nadaoka, K., Hino, M. and Koyano, Y., 1989, Structure of the turbulent flow field under breaking waves in the surf zone, Journal of Fluid Mechanics, 204, 359-387.

O'Donoghue, T. and Wright, S., 2004, Flow tunnel measurements of velocities and sand flux in oscillatory sheet flow for well-sorted and graded sands, Coastal Engineering, 51, 1163-1184.

Takeda, Y., 1995, Instantaneous velocity profile measurement by ultrasonic Doppler method, JSME Int. J., 8-16.

Watanabe, Y., H. Saeki and R. J. Hosking, 2005, Three-dimensional vortex structures under breaking waves, Journal of Fluid Mechanics, 545, 291-328. 